\title{
LOS LÍMITES DE LA INTERVENCIÓN PÚBLICA. INGENIEROS DE CAMINOS Y FERROCARRILES EN ESPAÑA (1840-1877)
}

\section{The limits of public intervention. Civil engineers and railways in Spain (1840-1877)}

\author{
RAFAEL BARQUÍN \\ Universidad Nacional de Educación a Distancia \\ rbarquin@cee.uned.es \\ CARLOS LARRINAGA \\ Universidad de Granada \\ clarrinaga@ugr.es \\ Cómo citar/Citation \\ Barquín, R. y Larrinaga, C. (2020). \\ Los límites de la intervención pública. Ingenieros de Caminos \\ y Ferrocarriles en España (1840-1877). \\ Historia y Política, 43, 27-56 \\ doi: https://doi.org/10.18042/hp.43.02
}

(Recepción: 20/05/2019; evaluación: 17/09/2019; aceptación: 06/11/2019; publicación: 13/05/2020)

\section{Resumen}

Entre las décadas de 1840 y 1870, los Gobiernos liberales españoles aprobaron un conjunto de iniciativas legislativas destinadas a construir y mejorar la infraestructura de transporte. Debido a la falta de recursos financieros, a menudo fue necesario recurrir al capital privado extranjero a través de varios sistemas de concesiones administrativas y ayudas públicas. Desde el enfoque profesional de los ingenieros civiles y ferroviarios, algunas de esas soluciones entraban en conflicto con sus posiciones ideológicas o con la realidad de unos proyectos que exigían grandes inversiones y 
prometían parcos retornos. Este artículo examina los supuestos de partida de esos ingenieros para hacer frente a los problemas, las respuestas que dieron, su acogida por los poderes públicos y la evolución de sus posiciones en las décadas centrales del siglo XIX.

\title{
Palabras clave
}

Ferrocarriles; concesiones administrativas; subvenciones públicas; España; siglo XIX.

\begin{abstract}
Between 1840' and 1870' decades, Spanish Liberal governments approved a set of legislative initiatives aimed at building and improving the transport infrastructure. Given the lack of financial assets, they often had to call to foreign private capital through several systems of state licenses and public aid. From the professional focus of civil and railway engineers, some of those solutions conflicted with their ideological positions, or with the reality of projects that demanded large investments and promised scant returns. This paper examines the underlying assumptions of these engineers to face the problems, the answers they gave, their acceptance by the public authorities, and the evolution of their viewpoints in the central decades of the 19 th century.
\end{abstract}

\section{Keywords}

Railways; state licenses; public aid; Spain; 19th century. 
I. INTRODUCCIÓN. II. LOS INICIOS DEL FERROCARRIL EN ESPAÑA. III. DE LA LEY GENERAL DE 1855 A LA CRISIS DE 1865-66. IV. DESDE LA CRISIS HASTA LA RESTAURACIÓN. V. CONCLUSIONES. BIBLIOGRAFía.

\section{INTRODUCCIÓN}

En el siglo XIx España se dotó de una red ferroviaria de una extensión considerable para el tamaño, población y riqueza del país ${ }^{1}$. Su construcción fue contemplada como un éxito del régimen liberal, y aún más como la victoria de un país sobre una geografía hostil ${ }^{2}$. Desde finales del siglo anterior existía una clara percepción de que la orografía era un problema importante para el desarrollo económico de España. Los fallidos y poco realistas intentos de construir una red de canales fueron un reflejo de esa preocupación. A lo largo de la primera mitad del siglo XIX se fue teniendo una visión más precisa del problema, conforme cartógrafos como Auguste Henri Dufour, Fermín Caballero o Francisco Coello iban perfilando los límites y cotas de rutas y ciudades $^{3}$. Con la aparición del ferrocarril llegó el turno de los constructores y los ingenieros de caminos.

El propósito de este artículo es analizar la posición de estos últimos ante el reto de la construcción ferroviaria, pero no desde una perspectiva técnica, sino económica. Lo que pronto se hizo evidente es que, por complicado que fuera levantar ferrocarriles en España, el verdadero problema era su rentabilidad, insuficiente para cubrir los costes de la construcción. De ahí que para atraer los capitales necesarios, de procedencia muy mayoritariamente extranjera, fuera necesario otorgar grandes facilidades legales y ayudas públicas 4 .

Visto desde la perspectiva del Gobierno y la opinión pública española, promover la construcción de un medio de transporte bajo tales condiciones parecería insensato. Pero existían dos convicciones que sobrepujaban todas las

\footnotetext{
$1 \quad$ Herranz (2008): 46-54.

2 Martykánová y Gilarranz (2020).

3 Un estado del conocimiento de la geografía urbana española en la época en Olazábal et al. (2019).

4 Castellvi y Barquín (2018): 466-476; Comín (1988): 372-383, y Herranz (2008): 120-121.
} 
dificultades. En primer lugar, la creencia de que el ferrocarril sería rentable por la simple captación del mercado del transporte; enseguida veremos que esta es la idea que subyace en el informe Subercase. Segundo, que el ferrocarril, una vez construido, construiría el país; es decir, que la anticipación de las infraestructuras de transporte sería, por sí misma, beneficiosa porque generaría nuevas oportunidades empresariales. En las siguientes décadas esas dos creencias se verían retadas por la realidad. Pero aún hoy el debate historiográfico en España sigue marcado por aquellas premisas. En todo caso, el problema técnico de la construcción no puede desligarse de los problemas económicos de la financiación y rentabilidad. Por su preparación y ocupación, la perspectiva de los ingenieros de caminos era una de las más valiosas a la hora de conocer esta problemática.

La periodización del ferrocarril en Espańa es bien conocida. En 1848 se inauguró el primero de la península ibérica, el Barcelona-Mataró. Hasta 1855 tan solo se habían puesto en explotación 477 kilómetros de vías férreas, pero desde la aprobación de la Ley General de Caminos de Hierro de ese año el ritmo de construcción creció de forma notable, alcanzándose en diciembre de 1866 los 4383 kilómetros ${ }^{6}$. Sin embargo, por entonces ya era evidente que, fuera de la misma construcción, el ferrocarril era un mal negocio, de modo que durante 1865 y 1866 todas las compañías ferroviarias entraron en quiebra técnica ${ }^{7}$. La construcción tuvo que paralizarse y no se reanudó hasta bien entrada la década de 1870, una vez concluidas las guerras carlista y cantonalista. En lo que restó de siglo la construcción siguió avanzando a buen ritmo, aunque sin alcanzar el del decenio 1855-1864. Por supuesto, hubo años malos y alguna crisis, pero ninguna tan seria como la de 1865-1866.

Dentro del conjunto europeo, la construcción de la red ferroviaria española fue tardía. El ferrocarril de Mataró se inauguró veintitrés años más tarde que la primera línea inglesa de Stockton a Darlington y veintiuno después que la primera francesa de Saint-Étienne a Andrézieux. Esto es un indicador más del atraso de la economía espańola; pero ese mismo atraso comportaba una ventaja: el ferrocarril ya era una tecnología probada. Y esto no solo afectaba a las máquinas, sino también a la organización de medios y personas. De ahí que hacia 1850 la bibliografía especializada ya hubiera definido los tres modelos básicos de desarrollo ferroviario: a) el modelo británico (o anglosajón), de

\footnotetext{
5 Es decir, sobre la conveniencia, o no, de construir anticipadamente las infraestructuras de transporte. Véanse Tortella (1982) y Nadal (1975). Para una revisión del debate, Muñoz (2018).

6 Memoria sobre las obras públicas (1870).

7 Tortella (1982): 183-200.
} 
limitada intervención pública, en el que las compañías privadas responsables de la construcción y explotación disfrutaban de una concesión indefinida, pero no recibían ayudas públicas, y que se aplicó en las Islas Británicas y Estados Unidos; b) el modelo belga (o alemán) de intervención amplia, en el que el Estado se hacía responsable de la construcción y explotación de, al menos, las líneas principales, y que fue el más frecuente en Europa Central y Oriental, y c) el modelo francés, intermedio entre los dos anteriores, en el que las compañías privadas recibían una concesión temporal, así como diversas ayudas públicas. Este modelo presentaba diferencias no pequeñas entre naciones por la cuantía y forma de entregar esas ayudas. Fue frecuente en la Europa meridional.

Como es sabido, España adoptó el modelo francés. A pesar de que el Estado hizo una contribución muy generosa a la financiación de la red e implementó ciertos instrumentos de supervisión de las obras, fue poco diligente en el control financiero de las ayudas y se abstuvo de construir o gestionar siquiera una parte de la red. En esto último, el contraste con nuestros dos vecinos, Portugal e Italia, fue muy acusado. Así, Portugal levantó una red de titularidad pública en dos amplias zonas del país, al sur del Tajo y al norte del Duero, donde el tráfico ferroviario era menor y, por tanto, el capital no estaba interesado en invertir. En la zona central, es decir, entre Lisboa y Oporto, operaron varias empresas privadas, la más grande de las cuales con diferencia era la Companhia Real dos Caminhos de Ferro. Esas empresas fueron auxiliadas con ayudas públicas ${ }^{8}$.

El caso italiano es más complejo y, en muchos sentidos, interesante. La primera red ferroviaria surgió alrededor de Milán en 1846 y fue de capital público, a imitación del modelo belga. En el resto del país la construcción recayó en compañías privadas subvencionadas. Con la reunificación, y en particular tras el boom constructor de 1861-1865, el nuevo Estado italiano optó por un modelo de grandes compañías privadas que se inspiraba en la ley francesa de 1858. Así, en 1865 la compañía estatal piamontesa, la principal del país y la única rentable, fue privatizada y reconvertida en la Compañía del Norte de Italia. Pero el ferrocarril italiano pronto mostró debilidades. Los conflictos entre las compañías y el Estado por el doble flujo de subsidios e impuestos fueron constantes, llevando a una paulatina nacionalización del sistema. Diez años después de su fundación y privatización, la Compañía del Norte de Italia fue nacionalizada. En 1881 y, de forma más clara, desde 1885 el sistema ferroviario italiano pasaría a ser mixto: las líneas eran de propiedad estatal que se alquilaban a compañías privadas?.

Santos (2011).

9 Schram (1997): 27-66. 
Existe otra diferencia importante entre el modelo español y el de esas dos naciones. En los tres países, las subvenciones empezaron a articularse mediante un sistema de garantía de interés. Sin embargo, en España, desde la ley de 1855, ese sistema fue sustituido por una subvención directa por kilómetro (al margen de otras ayudas), la cual serviría de base para la subasta de las concesiones. En Italia hubo cambios en la normativa, pero, en lo fundamental, las ayudas públicas se siguieron concediendo bajo la premisa de garantizar a las empresas una rentabilidad mínima. En Portugal se aplicaron los dos tipos de ayudas ${ }^{10}$.

En resumen, había varias soluciones financieras y contractuales al modo de enfocar la construcción ferroviaria. Incluso dentro del mismo modelo, había varias opciones no incompatibles entre sí. Este artículo trata de las posiciones adoptadas por los ingenieros ferroviarios españoles ante estas cuestiones y cómo respondió la dirigencia del país a sus propuestas.

\section{LOS INICIOS DEL FERROCARRIL EN ESPAÑA}

Hacia 1830 existía una percepción generalizada del atraso de la economía española, pero también de que los recursos públicos que podrían emplearse para superarlo eran ralos. El viejo sistema impositivo se mostraba incapaz de dar satisfacción a las necesidades del Estado, así como al reto del carlismo, de modo que una y otra vez se recurría al endeudamiento ${ }^{11}$. El problema del déficit público se doblaba con el del déficit comercial, así como los diversos problemas estructurales que afectaban a la competitividad de la industria.

Uno de esos problemas era el deficiente sistema de transportes ${ }^{12}$. Descartada la opción de los canales de navegación, el ferrocarril apareció como la opción más prometedora entre los pocos ingenieros en activo, casi todos militares ${ }^{13}$. Sin embargo, hasta la década de 1840 las realizaciones fueron nulas. Ni el absolutismo ni el primer liberalismo fueron especialmente receptivos a su implantación; pero, sobre todo, la guerra carlista paralizó los primeros proyectos ${ }^{14}$. Por cierto, esos proyectos carecían de planificación ingenieril. La Escuela de Ingenieros de Caminos no abrió sus puertas definitivamente hasta 1834, por lo que hubo que esperar a 1839 para que las promociones se sucedieran con regularidad ${ }^{15}$.

\footnotetext{
Santos (2011): 120-121.

Comín (1996): 73; Comín (2016): 122, y Fontana (1971, 1973).

Ringrose (1972).

Comín et al. (1998): I, 18-27.

Tortella (1982); Comín et al. (1998): I, 28-31, y Alcaide (1999).

15 Rumeu de Armas (1980): 277-314, 389-398 y 429-460, y Sáenz Ridruejo (1993): 47-81.
} 
En 1844 la solicitud de varios particulares para la construcción de ferrocarriles en Cataluña, Madrid y Asturias llevó al Gobierno a recabar información. Desde la recién creada Dirección General de Caminos se requirió a una Comisión de Ingenieros que elaborase un dictamen sobre el nuevo medio de transporte. Dicho dictamen sería elevado a la Junta Consultiva de Ingenieros de Caminos, Canales y Puertos, otro órgano de reciente creación. Los ingenieros encargados de redactarlo fueron Juan Subercase, inspector general de Caminos y director de la Escuela de Ingenieros de Caminos; Calixto Santa Cruz, el número uno de la primera promoción de 1839, y José Subercase, profesor de Ferrocarriles en dicho centro e hijo de Juan ${ }^{16}$. La Comisión partió del pliego de condiciones presentado por los solicitantes de una de esas líneas, Madrid-Cádiz ${ }^{17}$. El resultado fue el conocido como informe Subercase, fechado el 2 de noviembre de 1844, que a su vez fue la base de la Real Orden de 31/12/1844, la primera norma legal sobre ferrocarriles en Espańa.

Como luego sucederá con otros textos firmados por comisiones de ingenieros, el informe Subercase parte de la comparación de los tres modelos de desarrollo ferroviario citados, el anglosajón, el francés y el belga. En esta época, la experiencia italiana se encaminaba hacia el tercer modelo, mientras que la portuguesa era inexistente. Interrogándose sobre cuál de esos sistemas era el más conveniente, la Comisión se inclinaba por ejecutar los ferrocarriles con el belga, pues «es el único medio de que los ferrocarriles produzcan completamente el efecto que de ellos se debe esperar $\aleph^{18}$. Es importante comprender todo el razonamiento porque parte de una premisa que pronto se demostraría falsa: la supuesta gran rentabilidad del nuevo medio de transporte derivada de su competitividad. La Comisión creía que la construcción de un ferrocarril «destruye todos los demás medios de conducción que existían en la zona de terreno a donde alcanza la influencia del ferrocarril; y después de atraídos a esta vía todos los efectos transportables los conduce por ella sin competidor de locomoción y sin más freno en su exigencia que la tarifa estipulada $»^{19}$.

Es decir, abocaba al transporte a convertirse en un monopolio que, desde luego, no podía dejarse en manos de la iniciativa privada, tildada como «naturalmente egoísta $»^{20}$. En un mercado dominado por un monopolista privado el precio se situaría en un nivel superior al de equilibrio,

\footnotetext{
Sáenz Ridruejo (1990): 80-81.

Comín et. al (1998): I, 38.

Gaceta de Madrid, 28-1-1845.

Gaceta de Madrid, 29-1-1845.

Gaceta de Madrid, 28-1-1845.
} 
proporcionando al empresario enormes beneficios y solo pequeñas ventajas al conjunto de la sociedad. Nótese que el aspecto crucial de todo esto es la creencia de que, incluso con precios de equilibrio, el ferrocarril siempre sería una empresa rentable; extraordinariamente rentable si aprovechaba todo su poder de mercado.

Un correlato de lo anterior es que el ferrocarril nunca necesitaría ayudas públicas; tan solo una legislación que propiciase la expropiación de terrenos y otras facilidades menores. Esto explica por qué la Comisión descuida este asunto, que precisamente constituirá el centro del debate político de las siguientes décadas. El informe, tan prolijo en cuestiones técnicas menores, ni siquiera entra a valorar cuál sería el mejor sistema de subvenciones. Solo se dice que, llegado el caso, el Estado podría asumir una parte de los costes de construcción ("gastos de entretenimiento») en tanto en cuanto "el beneficio que estos fondos produzcan en el fomento de la riqueza pública indemnice completamente de aquel gasto, como podrá suceder en algunos casos ${ }^{21}$. Esta posibilidad es contemplada como algo excepcional, siendo preferible la construcción estatal, ya que «el dividendo de los Gobiernos consiste únicamente en el aumento de la riqueza pública y del bienestar de los gobernados; y he aquí la principal razón por la que una administración fuerte y acreditada es preferible a las compañías para la construcción de ferrocarriles $»^{22}$.

De modo coherente, el informe defiende el sistema belga de propiedad estatal, pero a renglón seguido lo considera impracticable debido a la situación financiera del Estado. De ahí que inmediatamente se ocupa del sistema francés de concesión administrativa. De nuevo, el foco es puesto en la desconfianza hacia el concesionario: cómo evitar que las empresas aprovechen indebidamente las ventajas técnicas del ferrocarril. La Comisión se pronuncia expresamente en contra de la «libre concurrencia», pues deriva en tal monopolio, y defiende la fijación por el Estado de tarifas de transporte, así como de cláusulas para el rescate de las líneas, algo que, al contrario que con las que subvenciona, nunca sucedió ni casi fue objeto de debate ${ }^{23}$.

Puede resultar chocante que representantes tan conspicuos del liberalismo como Subercase defendieran planteamientos de política económica tan poco liberales. Su informe parece estar más en consonancia con el reformismo ilustrado que con el liberalismo manchesteriano. Sucede que el liberalismo español de las primeras décadas de siglo es político antes que económico y también que la coherencia no es la característica primordial de su principal

\footnotetext{
21 Ibid.

22 Ibid.

23 Gaceta de Madrid, 29-1-1845.
} 
corriente en esos ańos, el moderantismo. Progresistas y moderados situaban el foco de debate mutuo en el alcance de la revolución liberal. Lo que caracterizó a los moderados fue el temor a que los excesos de la revolución acabasen con el mismo liberalismo. De ahí su firme defensa del orden y de cierta convivencia con las instituciones heredadas del Antiguo Régimen. Inevitablemente, esta posición conducía a traicionar el programa liberal, tanto en su vertiente política como en la menos visible vertiente económica. En cambio, el progresismo pudo hacer gala de una mayor coherencia con el liberalismo clásico. De ahí que la "escuela economista», que básicamente es una defensa de ese programa, sea un producto genuinamente progresista ${ }^{24}$.

El informe Subercase sería la base de la Real Orden de 31/12/1844, que debía regular la tramitación de solicitudes para la concesión de líneas. Aunque coincidente en mucho, la Real Orden se apartaba del espíritu del informe en algunos aspectos cruciales. En particular, el artículo $3 .^{\circ}$ introdujo las problemáticas "concesiones provisionales», que permitían a los particulares hacerse con los derechos de una línea ferroviaria durante doce o dieciocho meses sin la presentación de la documentación y los avales necesarios, siempre que los concesionarios fuesen personas «de conocido arraigo [que] ofrezcan además las garantías que el Gobierno estime suficientes». Por esta vía, los allegados políticos podían hacerse con unos derechos que, hipotéticamente, podrían dar grandes beneficios con su reventa o la emisión de acciones u obligaciones. Gracias a estas facilidades, en 1845 y 1846 se otorgaron veintiuna líneas, con un total de 6700 kilómetros. Su resultado práctico fue nulo. No habiendo capitales interesados ni en la recompra ni en la salida de títulos, casi todas las concesiones revertieron al Estado. Hacia 1847 solo subsistían cuatro (Barcelona-Mataró, Madrid-Aranjuez, Sama de Langreo-Gijón y Valencia-Játiva) con 186 kilómetros de raíles, de los que no se había tendido ni uno solo. Y es que los concesionarios, actuaran de buena o mala fe, pronto descubrieron que el bien sobre el que querían ejercer sus operaciones carecía de valor ${ }^{25}$. Tal y como había advertido en esos mismos años George Stephenson, en todo el país no

24 Gómez Ochoa (2007); Pan-Montojo (2006), y Romeo (1998). Las posiciones políticas de Subercase no son claras, pero nada hace pensar que en 1844 estuviese cerca de los progresistas. Al contrario, su carrera política desde 1834 estuvo vinculada a los moderados y, aunque ocupó breve e interinamente la Dirección General de Obras Públicas con Espartero, su promoción definitiva fue con Bravo Murillo. De todos modos, la impresión general es que en su carrera los factores políticos fueron menos importantes que los profesionales (Ferri, 2015): 88-99, y Sáenz Ridruejo (1990): 53-99.

25 Memoria sobre las obras públicas en 1867, 1868 y 1869 (1870): 6; Mateo del Peral (1978): 44; Comín et al. (1998): I, 41; Larrinaga (2005) y Barquín (2016): 291 
existía suficiente actividad para llenar un solo tren, una observación que, aunque exagerada, era premonitoria de lo que sucedería veinte años después ${ }^{26}$.

El fracaso de la real Orden 31/12/1844 llevó al Gobierno a solicitar a la Junta Consultiva un examen del estado de las líneas ferroviarias concedidas y a proponer medidas para acelerar su construcción. Se nombró una nueva comisión, en la que Juan Subercase también era miembro, que elaboró sendos informes sobre esas cuestiones. Sobre la base de esos documentos, el Gobierno presentó en 1848 un primer proyecto de ley general de ferrocarriles, siendo Juan Bravo Murillo ministro de Obras Públicas. En él se proponía incentivar la construcción garantizando los capitales empleados con un interés de no más del $6 \%{ }^{27}$. Aunque este proyecto de ley no salió adelante, el Gobierno hizo uso de sus facultades para promover ayudas en casos concretos, y así, el 12 de marzo de 1849, aprobó la primera subvención a un ferrocarril, el de Gijón a Sama de Langreo, con las condiciones allí señaladas.

Un año más tarde, el 10 de enero de 1850, el nuevo ministro de Fomento, Manuel Seijas Lozano, presentó al Congreso otro proyecto de ley general ferroviaria ${ }^{28}$. Una vez más se reconocía que la iniciativa privada difícilmente podría llevar adelante la construcción de líneas ferroviarias, por lo que, en un artículo de disposiciones transitorias, se ampliaban las ayudas hasta entonces concedidas. Al 6\% contemplado en el proyecto de Bravo Murillo se sumaba un $1 \%$ de amortización durante la vida de la concesión, que se fijaba en noventa y nueve años. Es decir, se aseguraba la amortización completa de la inversión. El proyecto no llegó a tramitarse, pero el 20 de febrero esas disposiciones transitorias fueron aprobadas en un real decreto, que se definía como provisional. En él se daba al Gobierno la facultad de otorgar provisionalmente concesiones ferroviarias $^{29}$. Como sucediera en 1845 , la norma generó otra oleada de solicitudes de concesiones ferroviarias. Ahora el tráfico de favores políticos era mayor, pues el objeto de la especulación no era una concesión administrativa sin verdadero valor, sino la posible subvención asociada.

26 Nadal (1975) y Cuéllar (2010).

${ }^{27}$ DSC, 1848, Apéndice al n. ${ }^{\circ}$ 70, pp. 1413-1418. Esa garantía de $6 \%$ se prolongaría durante las obras «y el número de años que se estime conveniente», siempre que la rentabilidad no alcanzase el $8 \%$.

28 DSC, 1850, Apéndice al n. 34, pp. 791-795.

29 Como se ve, las Cortes fueron muy diligentes en su tramitación. El proyecto de ley de artículo único fue aprobado el 15 de enero de 1850 (Diario de Sesiones de ese día, pp. 915-917). Entonces fue remitido al Senado, que lo aprobó el 29 de enero. Fue sancionado por la Corona el 15 de febrero, y publicado en la Gaceta de Madrid como Real Decreto, pese a haber sido aprobado por las Cortes el 22, con fecha de 20. 
Al tiempo que entraba en vigor ese real decreto, el Parlamento aprobó la constitución de una comisión destinada a estudiar el proyecto de ley de Seijas Lozano. Estaba presidida por Salustiano Olózaga y de ella formaron parte varios políticos y empresarios, así como el ingeniero Toribio de Areitio, que desempeñó un papel central por su dedicación y conocimiento de la materia. Ideológicamente, era una comisión equilibrada entre progresistas y moderados, pero quizás más inclinada hacia los primeros ${ }^{30}$. Para sus trabajos llamó a representantes de empresas, el Estado, el Ejercito y el cuerpo de ingenieros.

El conjunto de esas intervenciones y los informes elaborados en su desarrollo dieron lugar a un documento titulado «Información parlamentaria hecha por la comisión de ferro-carriles nombrada por el Congreso de los Diputados en 10 de Enero de 1850». Se trata de uno de los textos de mayor influencia en la conformación del sistema ferroviario español; incluso por encima del mucho más conocido informe Subercase. Es un texto irregular. El peso de las intervenciones fue muy variable en cuanto a la profundad y extensión de las respuestas. Por ejemplo, las opiniones de los militares, que eran muchos, fueron cortas y, con dos excepciones, irrelevantes. Esas excepciones realmente no son tales. Se trataba del general Antonio Remón Zarco del Valle y del brigadier Francisco Luján, quienes hablaban, ante todo, por su calidad de ingenieros o científicos ${ }^{31}$. Esos ingenieros sí tuvieron un papel destacado; tanto que algunos fueron vueltos a llamar. Eran Joaquín de Ezquerra, Francisco Antonio Echanove, Cipriano Segundo Montesino, Joaquín Alfonso Martí, Pedro Miranda, Juan Subercase, Calixto Santa Cruz, Constantino Ardanaz y Ramón Echevarría, a los que podrían agregarse los dos militares citados.

Los ingenieros no solo fueron interrogados sobre cuestiones técnicas, sino también sobre muchas otras de naturaleza económica. En general, se adhirieron al punto de vista del informe Subercase, según el cual la situación del erario hacía inviable la implantación del sistema belga, pese a sus muchas ventajas. En consecuencia, habría que recurrir a un sistema de concesiones. Los ingenieros más cercanos al progresismo fueron los más críticos con esta

30 Los otros miembros de la comisión fueron Patricio de la Escosura, Federico Esteban Vahey, Mateo de Murga, Manuel Antonio Lasheras y Luis María Pastor como secretario. Olózaga, Murga y Escosura estaban encuadrados en el liberalismo progresista, mientras que Vahey, Areitio y Pastor eran moderados, si bien el último se acercaba a los progresistas.

31 De los treinta y cinco informantes, trece eran militares, pero lo que dijeron solo ocupa 35 de 252 páginas. De ellas, diez corresponden a Luján y siete a Zarco del Valle. 
posición. Por ejemplo, Joaquín Alfonso, quien defendía una «libertad absoluta» en las relaciones económicas, ni siquiera veía necesaria la existencia de una legislación específica para el ferrocarril. Lo deseable sería que cualquier particular, lo mismo que el Estado, pudiera estudiar, construir y explotar una línea ferroviaria sin restricciones ni ayudas. Esta alusión al Estado como inversor es pertinente porque, como el propio Alfonso señalaba, en la práctica su propuesta acabaría asemejándose a un sistema belga ${ }^{32}$. Otro ingeniero progresista, Ardanaz, mantuvo una posición parecida. Consideraba que el Estado debería entregar a las compañías la plena propiedad de los ferrocarriles, es decir, a perpetuidad, y no la concesión por un período de tiempo más o menos largo. Las empresas propietarias estarían obligadas a alquilar la vía a los transportistas particulares, si los hubiere, como instrumento para lograr la «máxima concurrencia» ${ }^{33}$. Nótese la enorme distancia que separa a Subercase de Alfonso o Ardanaz.

En lo que todos los ingenieros se mostraron de acuerdo fue en rechazar las concesiones provisionales, lo cual no dejaba de ser una postura notable dado que el decreto de 20 de febrero las acababa de legalizar. Además, el cuestionario sobre el que se sostenía la información parlamentaria incidía en varias de sus preguntas en este tema. Pareciera que la Comisión tratase de encontrar en los informantes el respaldo a una propuesta que ya era norma legal.

Los ingenieros más favorables al modelo francés lógicamente también creían que el Estado debía asumir parte del esfuerzo inversor, pero las opiniones variaban bastante en cuanto al concepto y cuantía de las ayudas. Así, Francisco Antonio Echanove pensaba que la subvención del $6 \%$ aún era insuficiente, por lo que creía que el Estado también debía asumir el coste de los estudios de las líneas y las obras de fábrica y explanación. Solo cuando esas obras hubiesen concluido, se debería licitar la línea ${ }^{34}$. En cambio, Pedro Miranda y Ramón Echevarría eran partidarios de encargar al Gobierno la ejecución de los estudios preliminares de los principales ferrocarriles, pero no la construcción como tal ${ }^{35}$.

La Comisión igualmente interrogó sobre el futuro plan ferroviario. Presentó a los informantes seis hipotéticas líneas que desde Madrid alcanzaban los extremos del país y les preguntó sobre cuáles debían construirse en primer lugar. Implícitamente quedaba claro que las elegidas también serían las que recibirían ayudas públicas. En este tema, la Comisión parece haber

\footnotetext{
Congreso de los Diputados. Comisión de Ferro-carriles (1850): 71-72

Ibid.: 32-34

Ibid.: 132.

35 Ibid.: 23 y 43.
} 
manifestado un verdadero interés por resolver los detalles, motivo por el que llamó varias veces a Ardanaz y Echevarría. La propuesta final fue una red mínima en la que la línea de Madrid a Irún sería prioritaria; no hubo mayor concreción $^{36}$.

\section{DE LA LEY GENERAL DE 1855 A LA CRISIS DE 1865-66}

La «Información parlamentaria» concluyó en junio y, a corto plazo, sus resultados fueron nulos. Seijas Lozano cesó en sus funciones en noviembre de $1850^{37} \mathrm{y}$ a finales de ese mismo ańo la estrategia del Ejecutivo cambió por completo. Se decidió relegar el sistema de concesiones para las líneas de menor importancia, mientras que las de primer orden se construirían por cuenta del Estado y con contratas. Es decir, abogaba por un sistema belga en el preciso momento en que este se implementaba en el norte de Italia. Esta reorientación se ajustaba a las propuestas de los ingenieros; otra cosa es que ellos mismos la considerasen viable. No obstante, había dos reparos importantes. Primero, los progresistas consideraban que, en caso de optarse por tal sistema, lo primero que habría que hacer era aprobar un plan ferroviario que determinase qué líneas eran prioritarias y debían construirse antes que las demás. Segundo, pesaba la sospecha de que este giro en la política económica obedecía a intereses inconfesables, o sea, a la influencia política de José de Salamanca, el principal o único beneficiario de aquellas contratas. La pequeña historia de los escándalos financieros del trienio 1851-1854 confirmó esas sospechas ${ }^{38}$.

La mala praxis del Gobierno en la gestión del sistema ferroviario avivó el debate político. De nuevo fueron los ingenieros próximos al progresismo los que se mostraron más críticos con el rumbo que estaban tomando las cosas, abogando por la no injerencia del Estado. Por ejemplo, en un artículo publicado en 1853 en la Revista de Obras Públicas ${ }^{39}$, el ingeniero Ángel Retortillo afirmaba que «nunca estará mas comprometida la libertad individual y la independencia nacional, que en el caso de dejar en manos del Estado la propiedad y explotación de las vías férreas. Esta vasta industria necesita [...] la mayor libertad posible y no estar expuesta a las influencias de la política interior e internacional, y mucho menos a las fluctuaciones del tesoro» ${ }^{40}$.

\footnotetext{
36 Barquín (2016): 293-294; Mateo del Peral (1978): 61-69, y Cordero (1978): 197-210.

37 Mateo del Peral (1978): 69-70.

38 Ibid.: 70-74, y Comín et al. (1998): I, 51-54.

39 Un análisis de su universo ideológico en Martykánová (2007).

40 Retortillo (1853): 26
} 
Esta línea de pensamiento, ya recogida por Ardanaz y Alfonso en la Comisión Olózaga, será conocida como "escuela economista» ${ }^{41}$. Unos años más tarde encontrará en Gabriel Rodríguez y José Echegaray a sus principales representantes. Estos ingenieros progresistas empleaban los argumentos del liberalismo clásico para defender un modelo ferroviario de tipo anglosajón, en el que las compañías serían propietarias de las líneas que estarían obligadas a ceder en peaje a los transportistas interesados y en el que la contribución del Estado a la construcción debía ser poca o nula ${ }^{42}$.

Por otro lado, los trabajos dirigidos a elaborar un plan ferroviario no se concretaron en nada. En el primer lustro de la década de 1850 por dos veces se intentó la aprobación de planes dentro de leyes generales de ferrocarriles. El primer intento vino con el proyecto de ley ferroviaria del ministro de Comercio Mariano Miguel Reinoso, presentado en diciembre de 1851. Su plan ignoraba las conclusiones de la Comisión, proponiendo una red interior y centrada en Madrid, que sería auxiliada por canales y ríos navegables. Lo cierto es que todo el proyecto era poco realista y estaba mal justificado ${ }^{43}$. El segundo intento vino del ministro de Fomento Agustín Esteban Collantes. En su plan ferroviario se volvía al espíritu de la Comisión de 1850, pero sin apenas concreción. En realidad, ese plan era poco más que la enumeración de las seis líneas principales planteadas por la Comisión Olózaga ${ }^{44}$.

Entonces estalló la Revolución de 1854. Aquel movimiento fue bien recibido por gran parte de los ingenieros de caminos. Por ejemplo, Arturo de Marcoartu se felicitó de que «la patria» hubiese hecho un "heroico esfuerzo para destruir las carcomidas bases de nuestra organización política y administrativa ${ }^{45}$. A la luz de lo sucedido en los años anteriores, era apremiante la aprobación de una nueva ley y un nuevo plan de ferrocarriles. Pero pasaron algunos meses antes de que el Ejecutivo se decidiera a tomar cartas en el asunto, pues se quería resolver antes la espinosa herencia de las contratas de dudosa legalidad. Además, pendía el problema de la determinación de las líneas.

En este contexto el nuevo ministro de Fomento, Francisco Luján, remitió a las Cortes Constituyentes un tercer proyecto de ley general de ferrocarriles. La comisión de diputados elegida para dictaminar sobre él estaba formada por cinco funcionarios, de los que solo dos eran ingenieros de caminos: José

41 Martín Rodríguez (2006): 14-27, y Ramos Gorostiza y Martínez Vara (2008): 12-14.

42 Martykánová (2016): 59-60.

43 DSC, 3-12-1851, Apéndice, pp. 2017-2037. Barquín (2016): 294. Sobre las razones de tal diseńo, Reinoso (1853-57): 135-139.

44 DSC, 21-11-1853. pp. 43-46. Memoria (1867): 18.

45 Marcoartu (1854): 205. 
García Otero y Cipriano Segundo Montesino ${ }^{46}$. Pero los conocimientos sobre el ferrocarril del primero, un antiguo ingeniero militar especializado en obras hidráulicas, eran muy inferiores a los de Montesino, cuya trayectoria científica era abrumadora y que, además, desempeñaba un cargo público relevante, director general de Obras Públicas ${ }^{47}$. El dictamen de la Comisión fue presentado al Parlamento en 20 de marzo de $1855^{48}$. Los debates se extendieron hasta el 25 de mayo. El principal punto de discusión giró alrededor del artículo 2..$^{\circ}$ del dictamen. La redacción original enumeraba ocho líneas de «primer orden» que, grosso modo, perfilaban el mapa ferroviario final. Muchos diputados intervinieron para proponer cambios que favoreciesen las provincias que representaban. En cambio, un joven Práxedes Mateo Sagasta apoyó la redacción original precisamente para impedir la proliferación de líneas. La redacción final, obra del propio Montesino, fue, como enseguida veremos, aún más vaga de la que proponía el dictamen ${ }^{49}$.

La Ley General de Caminos de Hierro de 3 de junio de 1855 supuso un antes y un después en la historia del ferrocarril en España. En primer lugar, por el extraordinario impulso que dio a la construcción. Las subvenciones y garantías estatales, las expectativas de grandes beneficios en la explotación y la certeza de sustanciales ganancias en la construcción animaron a los inversores extranjeros. Pero, además, supuso un cambio radical en la estructura de concesiones administrativas y ayudas públicas. No es este el lugar para hacer una descripción detallada de la ley, pero sí para destacar ciertos elementos. Esta aspiraba a eliminar la arbitrariedad en las decisiones de los responsables políticos y a evitar que se repitieran los recientes escándalos político-financieros; pero también quería que los inversores actuasen libres de injerencias estatales y se moviesen en un entorno propicio. En consecuencia, apostó por la concesión administrativa a empresas privadas como principal (o único) sistema de construcción y explotación de las líneas y por un generoso sistema

46 Gaceta de Madrid, 25-8-1854. Los otros miembros de la Comisión fueron José Caveda, director general de Agricultura, Industria y Comercio; Tomás Ibarrola, oficial del Ministerio de Fomento, y Eleuterio Oteo, abogado consultor del mismo.

47 García Otero fue director general de Obras Públicas en 1847 y desempeñó un papel crucial en la elección del paso del ferrocarril del Norte. Barquín (2012): 148-150, y Sáenz Ridruejo (1990): 134. Montesino, ingeniero de la École Centrale des arts et manufactures en París, tenía experiencia ferroviaria en la línea Madrid-Aranjuez. En los años siguientes seguiría desempeñando trabajos de dirección en otros ferrocarriles. Wais (1974): 191-192, y Martínez-Val (2001): 54-55 y 201-202.

48 DSC, 20-3-1855. Apéndice sexto (3089 a 3093).

49 DSC 21-5-1855. Mateo del Peral (1978): 90-99. 
de subvenciones. Asimismo, estableció la obligatoriedad de una ley específica para cada concesión. La iniciativa en la propuesta de nuevas líneas correspondería tanto al Gobierno como a las empresas. En fin, la misma ley y, sobre todo, el reglamento y la legislación anexa, otorgaban al Estado una considerable capacidad de inspección y control sobre las obras y las concesiones ${ }^{50}$.

Uno de los efectos de la aprobación de la nueva ley fue la atenuación de los debates surgidos en el lustro anterior en torno a la cuestión ferroviaria. En parte, esto puede atribuirse a que la norma ofrecía fuertes garantías jurídicas y proporcionaba un escenario más sencillo. Aunque se contemplaban otros procedimientos de ayudas públicas, en la práctica la subvención kilométrica acabó articulando todo el proceso de concesión en subasta pública, pues era la mejor solución para todos los agentes implicados. La subvención kilométrica era ventajosa para las empresas porque proporcionaba liquidez con la terminación de las obras, e incluso antes, mediante los «anticipos reintegrables». Desde la perspectiva del Estado y de la opinión pública también era preferible porque no requería la colaboración de las empresas en la presentación de unos estados contables confiables.

Sin embargo, la ley también tenía una clara deficiencia: no venía acompañada de un plan ferroviario. Tan solo establecía una distinción entre ferrocarriles de servicio general y particular, siendo los primeros de dominio público y, por tanto, subvencionables. Algunos de ellos, los que "partiendo de Madrid, terminen en las costas o fronteras del reino», serían además considerados «de primer orden». Pero esta segunda clasificación era poco más que una declaración de intenciones, pues su único efecto era evitar un trámite administrativo irrelevante: la presentación de una información pública sobre su utilidad. En resumen, todas las grandes y medianas líneas del país eran de servicio general y podían recibir ayudas del Estado. Nótese que la ausencia de un plan era el mejor escenario para las compañías ferroviarias, ya que, al no señalar qué líneas eran susceptibles de recibir ayudas y cuáles no, abría la puerta a que todas las recibiesen. Dado que se reconocía la iniciativa privada en la propuesta de líneas, lo habitual fue que la misma compañía que se interesaba por un determinado trayecto realizara los estudios previos, ganara la concesión en subasta pública y recibiera las pertinentes subvenciones ${ }^{51}$.

Con el nuevo marco normativo el Estado intervenía en todas las fases de la concesión y construcción del ferrocarril como garante del cumplimiento de la ley antes que como fiscalizador, pero su principal papel era otro: la de financiador de las obras, no solo por la generosa cuantía de las

50 Ibid.: 93-100, y Comín et al. (1998): I, 56-59.

51 Cordero (1978): 198-200. 
subvenciones kilométricas, sino también por otros dos tipos de ayudas: los anticipos de subvenciones y las subvenciones auxiliares. Tampoco es este el lugar adecuado para detallar esas ayudas, pero sí es importante destacar que, en tanto en cuanto el dinero fluyó del Estado a las compañías, la opinión pública estuvo relativamente tranquila.

\section{DESDE LA CRISIS HASTA LA RESTAURACIÓN}

Pero las dificultades a las que se enfrentaba el ferrocarril en España eran muy serias. Los problemas eran de naturaleza diversa: la complejidad técnica de la propia construcción, la debilidad del entramado financiero, etc., si bien el más grave, y la raíz última de todos, era la falta de tráfico. Esta había sido la causa fundamental de que las concesiones otorgadas al amparo de la Real Orden de 1844 no fructificasen. Con muy pocas excepciones, ninguna de las grandes líneas captaba o generaba suficiente actividad como para ser rentable y solo el poderoso auxilio de las subvenciones había posibilitado que se construyesen. No obstante, tanto los inversores iniciales como los que, incautamente, se fueron uniendo, confiaban en que el ferrocarril terminaría siendo una empresa rentable. Esta creencia se fundaba en la experiencia de los ferrocarriles franceses, en los que las mejores oportunidades de negocio ferroviario fueron apareciendo a medida que los recorridos se extendían. Se pensaba que en España esas oportunidades surgirían con el cierre de la red.

Dicho cierre sucedió alrededor de $1863^{52}$. Tal y como estaba previsto, en 1864 los ingresos de explotación de las grandes compañías crecieron con fuerza: un $40,5 \%$ con respecto al año anterior. Pero no lo hicieron en absoluto en 1865 y 1866. A lo largo de esos dos años fue extendiéndose entre la opinión pública un estado de creciente ansiedad, que se convirtió en pánico cuando empezaron a quebrar los primeros bancos. Intentando calmar los ánimos, publicaciones como Revista de Obras Públicas y Gaceta de Caminos de Hierro, las memorias de las juntas de accionistas e incluso las actas de los consejos de administración recogían en esos años multitud de cuadros estadísticos acerca de la explotación de las compañías extranjeras, con la evidente intención de presentar la situación como una tormenta pasajera sin mayores consecuencias. Se daban explicaciones circunstanciales al estancamiento de los tráficos: la

52 En 1863 se inauguraron los últimos tramos de las principales líneas del norte que enlazaban las capitales vascas con Barcelona y Madrid por Zaragoza, así como varias líneas del sur, si bien el acceso completo no se cerró hasta abril de 1865. Las líneas de Valencia y Alicante estaban abiertas desde 1859 y la de Cartagena desde 1862. 
crisis financiera internacional, el «hambre del algodón» causada por la guerra de Secesión norteamericana, las malas cosechas de cereales, la epidemia de cólera de 1865 y, ya en 1866, la quiebra de la banca Overend and Gurney, las guerras austro-prusiana y tercera de independencia italiana o unas circunstancias políticas mal definidas o exageradas como «graves y repetidas alteraciones del orden público en el interior» y la «insurrección militar» (pronunciamiento de Villarejo de Salvanés) ${ }^{53}$. Más o menos ciertas, todo eran excusas. Pero quizás lo peor era que las más verosímiles eran consecuencias antes que causas. La crisis de la banca provincial en España tenía su origen en la mala gestión de las entidades, pero también en el fracaso del negocio ferroviario ${ }^{54}$.

En esos ańos de paso de la euforia al pánico se elaboraron varios informes sobre el futuro plan ferroviario español. Su eficacia última fue, como veremos, muy reducida. No obstante, las deliberaciones son un buen observatorio de las posiciones de los ingenieros en materia ferroviaria. Y es que detrás de la aparentemente técnica e inocua voluntad de elaborar un plan ferroviario, yacía una cuestión más importante: qué líneas ferroviarias podrían recibir ayudas públicas y en qué orden y cuáles no.

La iniciativa en esta investigación nació el 13 de enero de 1864. Constantino Ardanaz y otros seis diputados presentaron un proyecto de ley en el que se solicitaba un crédito de dos millones de reales para elaborar un estudio que apartara «de la arena de la discusión política cuestiones que se han traído a ella con demasiada frecuencia ${ }^{55}$. Desde el punto de vista de las compañías, la inexistencia de un plan era una situación imposible de mejorar. De ahí que la mera tramitación del proyecto de ley contara con los votos negativos de Bertrán de Lis y Salamanca, representantes de las compañías ferroviarias. Pese a esa oposición, el 10 de marzo Ardanaz consiguió la aprobación de su proyecto de ley por abrumadora mayoría ${ }^{56}$.

Para llevarla adelante se decidió la constitución de una comisión que sería conocida como Comisión de Ingenieros, aunque también como Comisión Ardanaz, un nombre equívoco pues él no participaba en ella. Sus miembros fueron designados desde la Dirección General de Obras Públicas, que acababa de estrenar titular en el diputado gallego Frutos Saavedra Meneses, de la Unión Liberal. Saavedra llegó al ministerio de la mano del nuevo ministro de Fomento, el también diputado gallego del mismo partido Augusto

53 Norte, Actas del Consejo de Administración, 1863, p. 11 y 1864, p. 12, 1865, pp. 7 y 8,1866 , p. 1,1867 , p. 1 y 4.

54 Tortella (1982): 183-200.

55 DSC 10-3-1864, p. 1130.

56 DSC 10-3-1864. Un resumen de dicho debate en Comisión especial, 1867: 111-121. 
Ulloa y Castañón, que tenía un perfil más progresista. Los comisionados fueron los ingenieros Calixto Santa Cruz, Carlos María de Castro, Jacobo González Arnao y, como secretario, Gabriel Rodríguez. Este último seguramente fue quien cargó con el trabajo material de redactar el documento ${ }^{57}$. Rodríguez era profesor de la Escuela de Ingenieros en la que Santa Cruz era director. Había trabajado con González Arnao en varios proyectos y era coautor de un trabajo con el significativo título de Memoria sobre los medios de reducir los gastos de primer establecimiento ${ }^{58}$. En ella se arguye que estos no debían reducirse mediante ayudas públicas, pues con ello solo se consigue «una traslación de la pérdida de capital, que en lugar de pesar sobre las empresas recaerá sobre las clases contribuyentes del país" ${ }^{59}$.

$\mathrm{El}$ informe que elaboró la Comisión de Ingenieros, el primer anteproyecto del plan de ferrocarriles, tiene firma de 25 de junio de $1864^{60}$. Comienza presentando el «Objeto del Plan», que era «introducir orden y regularidad en la concesión de nuevas líneas» con dos propósitos. Primero, lograr que los recursos del Estado se empleasen en las líneas necesarias "y no se desparramen y desperdicien en la ejecución de las líneas de interés secundario, o quizás puramente de localidad.» Segundo, hacer que las nuevas líneas «no puedan ser un obstáculo a la buena explotación de las ya concedidas». Es decir, operen en condiciones de monopolio $^{61}$. La prioridad era reducir el coste, o sea, las ayudas públicas. De ahí que se criticase a quienes defendían la construcción irrestricta de nuevas líneas con apoyo estatal: «Esas personas olvidan que el ferrocarril, como todo instrumento industrial, puede costar más de lo que vale, en cuyo caso disminuye la riqueza en vez de fomentarla, y que el sistema de subvenciones adoptado en nuestro país tiene precisamente el inconveniente de que facilita con frecuencia la ejecución de ferrocarriles que valen mucho menos de lo que cuestan ${ }^{n 62}$.

57 A él se debe su enfoque marcadamente económico, o no solo técnico, de la Escuela de Ingenieros en Madrid, que también se seguía en las grandes écoles de ingenieros de Francia. Rodríguez se servía de los textos de los economistas académicos liberales franceses ligados al Journal des Économistes. Sáenz Ridruejo (1990): 232-234 y 242, y Martín Rodríguez (2006): 14-36.

58 Hay un tercer firmante, el ingeniero Luis Torres Vildósola, también progresista. Arnao y Rodríguez trabajaron juntos en 1864 en el estudio del mejor paso del ferrocarril por el Pirineo Central, Cien años del ferrocarril en España (1948): 226. La necrológica de González Arnao en Revista de Obras Públicas, 1895: 122.

59 González Arnao et al. (1866-1867): 348.

60 Comisión de Ingenieros (1864). Resúmenes en Revista de Obras Públicas (1864), 17, 18, 19 y 20, y Comisión Especial (1867): 124-130.

61 Comisión de Ingenieros (1864): 7.

62 Ibid.: 32-33. 
El anteproyecto de la Comisión de Ingenieros propuso la construcción de un número relativamente pequeño de nuevas líneas con 3814 kilómetros. De ellos, 3034 serían de primera categoría y 780 de segunda, lo que básicamente significaba que los primeros deberían construirse antes que los segundos ${ }^{63}$. Los menores incrementos tendrían lugar en la red del Norte, donde solo se preveían abrir 186 kilómetros. En la del Noroeste serían otros 400 kilómetros, mientras que en cada una de las otras cuatro redes las nuevas líneas oscilarían entre 731 y 894 kilómetros $^{64}$. En resumen, allí donde la construcción sería más cara por las mayores dificultades orográficas, también era donde menos líneas se abrirían. Al final del proceso, se alcanzaría los 10618 kilómetros. Sin embargo, es importante advertir que antes que licitar las nuevas líneas había que terminar los 3138 kilómetros pendientes en las anteriores concesiones. Significativamente, el informe no hace mención a plazos de construcción.

Como era preceptivo, el informe de la Comisión de Ingenieros fue elevado al órgano rector del cuerpo, la Junta Consultiva. De ella formaban parte tres de los cuatro miembros de la misma Comisión — faltaba Rodríguez-, los cuales, lógicamente, votaron a favor de su propio informe. También lo hizo el presidente, Francisco Barra, así como Ramón Echevarría, quien participó con Ardanaz en la Comisión de $1850^{65}$. Pero los otros miembros de la Junta, Elías Aquino, Julián Noguera, Toribio de Areitio, Agustín Elcoro, Rafael López, José Subercase y Joaquín Núñez de Prado votaron en contra. Por tanto, el informe fue rechazado. No solo eso: la Junta decidió elaborar un contrainforme ${ }^{66}$. Desde luego, todo esto era excepcional. Más aún teniendo en cuenta que en la minoría de cinco votos se encontraba el mismo presidente y la mayor parte de los ingenieros que, por su experiencia, podrían

63 En rigor, las primeras serían aquellas que atendieran a "las necesidades desatendidas de una manera completa o casi completa», y las segundas «las que tienen por principal, si no exclusivo objeto, ampliar y mejorar la satisfacción ya conseguida». Ibid.: 8.

64 Ibid.: 31 y cuadros 13 y 14.

65 Los cinco emitieron votos particulares. El de Barra, Santa Cruz y González Arnao fue conjunto y breve, manifestando su respaldo al antiguo plan y, además, la queja por la ausencia de datos. Castro, coincidiendo con los anteriores, insistió en la cuestión de los Alduides. El voto de Echevarría fue muy extenso, conformando una especie de ampliación del plan de la Comisión de Ingenieros. Junta Consultiva de Ingenieros de Caminos, Canales y Puertos (1864): 73-82.

66 Junta Consultiva de Ingenieros de Caminos, Canales y Puertos (1864). También en Revista de Obras Públicas (1864), 21, 22, 23 y 24 y 1865, 1. Amplio resumen en Comisión Especial (1867): 130-140. 
considerarse «ferroviarios» ${ }^{67}$. Es significativa la presencia de perfiles moderados en esos votos contrarios (Subercase, Areitio o Nuñez de Prado, de la Unión Liberal).

La mayoría de la Junta tenía una idea menos positiva acerca del diseño general de la red que la minoría y consideraba que algunas líneas «adolecen de graves defectos en la determinación de sus direcciones generales» ${ }^{68}$. No obstante, tales defectos no debían impedir la construcción de nuevas líneas, incluso si entraban en competencia con las ya existentes. A pesar del esfuerzo realizado, muchas ciudades y comarcas del país habrían quedado desatendidas, por lo que era necesario ampliar la red mediante un nuevo grupo de líneas más o menos trasversales; y dos de ellas, costeras, entre las provincias de Lugo y Guipúzcoa y Murcia y Cádiz. En resumen, las nuevas líneas sumarían 5381 kilómetros, de modo que el conjunto de la red alcanzaría los 12248 kilómetros ${ }^{69}$.

Una cuestión interesante es el coste presupuestado en cada plan. El de la Comisión de Ingenieros ascendía a 1393 millones de pesetas, una cifra muy similar al de la Junta, 1353 millones $^{70}$. Dado que la Junta preveía construir un $50 \%$ más de líneas que la Comisión, necesariamente uno de los dos informes estaba errado. $\mathrm{Y}$ a tenor de lo que sucedió en las vías que se fueron abriendo en los siguientes años, parece claro que las estimaciones de la Comisión estaban más ajustadas a la realidad. Desde la perspectiva del Estado, la construcción de más líneas implicaría más subvenciones ordinarias. Con casi completa seguridad, su monto por kilómetro no sería inferior al de las ya aprobadas, pues tendrían menos tráfico y, por tanto, los licitadores de cada concesión apenas podrían rebajar la postura inicial de la subasta. Según el examen que al respecto hizo la Revista de Obras Públicas de los dos anteproyectos, las ayudas públicas serían de unas 57500 pesetas por kilómetro, poco menos que las 60000 habituales $^{71}$. Por supuesto, a esas subvenciones ordinarias habría que añadir las auxiliares (que con la legislación existente rondarían el 50-60\% de aquellas), el coste financiero de la deuda ferroviaria que hubiera que emitir, el de los anticipos, etc.

67 Los dos junteros que votaron con la comisión, Barra y Echevarría, tenían esa experiencia. De los que votaron en contra la tenían Subercase, Núñez de Prado y Rafael López.

68 Junta Consultiva de Ingenieros de Caminos, Canales y Puertos (1864): 42

69 Ibid.: 42-49, 69 y cuadros 1 a 13.

70 Junta Consultiva de Ingenieros de Caminos, Canales y Puertos (1864): 69 y cuadro 13; Comisión de Ingenieros (1864): 31, y cuadros 13 y 14.

71 Además de publicar los dos anteproyectos, la redacción de la Revista de Obras Púbicas publicó un artículo extenso en dos números (1865, 7 y 9). 
En definitiva, los principios que guiaban el trabajo de la Junta eran muy distintos de los de la Comisión. La Junta se propuso averiguar qué ferrocarriles necesitaba el país sin preocuparse demasiado por los costes, que se estimaron a la baja. Ante todo, había que resolver un problema explicitado con cursiva del siguiente modo: «Fijar la red de ferrocarriles que en un plazo prudencial pueda ejecutarse y satisfacer las necesidades de la Peninsula en sus relaciones comerciales interiores y exteriores ${ }^{72}$. Este objetivo era urgente. Aunque a lo largo del informe no se señalan plazos, se insiste en la premura. Aduciendo que no se disponía de suficiente información, la Junta no estableció ninguna clasificación ni orden de preferencia en la construcción de las nuevas líneas. En cambio, insistió expresamente en dotar a las de primera importancia (sin especificar cuáles) de "auxilios inmediatos y efectivos», que se extenderían, aunque más tarde, a las demás líneas ${ }^{73}$. En resumen, la prioridad era el tiempo, no el coste.

Los dos informes, junto con el resto de los datos recabados, fueron sometidos a una «Comisión Especial» que acabaría respaldando a la Comisión de Ingenieros. Dada la experiencia anterior (y la futura), este desenlace resulta inesperado, pero tampoco las circunstancias bajo las que trabajó esa Comisión fueron normales. En el momento de redacción del informe y el contrainforme (primavera de 1864) la situación financiera de las compañías era incierta, pero la quiebra aún parecía lejana. Pero a lo largo del segundo semestre de 1864 y el primero de 1865, las perspectivas de las compañías ferroviarias empeoraron mucho. Bajo tales circunstancias plantear la construcción de nuevas líneas resultaba quimérico.

Por otro lado, la misma composición de la Comisión Especial tampoco era proclive a una expansión de la red. Su presidente, Manuel Gutiérrez de la Concha, marqués del Duero, era un destacado militar y liberal moderado hondamente preocupado por la moralidad en el sistema de concesiones. Como la Comisión Especial era muy numerosa (38 junteros, un secretario y dos auxiliares), su primera decisión fue constituir una subcomisión que elaborase un borrador ${ }^{74}$. A ella no fueron llamados ninguno de los miembros de la Junta que votaron el contrainforme, a pesar de que tres de ellos, Elcoro, Núñez de Prado y Areitio, formaban parte del pleno de la Comisión Especial. Más aún, cuando unos meses más tarde hubo que nombrar a otro ingeniero, se eligió a

72 Junta Consultiva de Ingenieros de Caminos, Canales y Puertos (1864): 41.

73 Ibid.: 49.

74 Comisión Especial (1867). La presentación de los miembros de la Comisión al comienzo del informe (pp. III y IV) se completa con algunas indicaciones sobre los debates (148). 
Mariano de Castro, quien solo discrepaba de los miembros de la Comisión de Ingenieros por su tenaz defensa del ferrocarril de los Alduides. Quien sí fue convocado a la subcomisión fue Calixto Santa Cruz, que también estuvo en la Comisión de Ingenieros, así como dos ingenieros cercanos al progresismo, Constantino Ardanaz y Eusebio Page. El primero ya había mostrado su preferencia por las redes mínimas en la comisión de $1850^{75}$. El gaditano Page era amigo íntimo de Sagasta. Más significativo incluso es el hecho de que había sido nombrado en sustitución de Gabriel Rodríguez, que declinó actuar como secretario por problemas de salud. Es de suponer que le sustituyera alguien de su plena confianza. El resto de los miembros de la subcomisión tenían perfiles políticos poco definidos, a excepción de Manuel García Barzanallana, liberal moderado como el marqués del Duero.

Una circunstancia que pesó en el trabajo de la subcomisión fue la muerte por cólera de dos de sus miembros en el verano de 1865, Santa Cruz y Olea. Según indica el informe final, «tanto por estas lamentables desgracias como por la ausencia de los otros miembros de la subcomisión", hubo que hacer nuevos nombramientos. Fueron designados Facundo Infante y Joaquín de la Gándara en representación de las empresas concesionarias, el director general de impuestos indirectos Augusto Amblard, el geógrafo Francisco Coello y, como se ha indicado, el ingeniero Mariano de Castro. Estos cambios seguramente retrasaron el trabajo de la subcomisión, que no pudo presentar su informe hasta diciembre de 1865, es decir, en el preciso momento en el que las compañías ferroviarias se hundían en el abismo.

El informe de la subcomisión fue refrendado por el pleno sin, al parecer, mayores resistencias. La ausencia de una respuesta organizada pudo deberse a su mismo tamaño y a que participaban un buen número de ingenieros sin experiencia en ferrocarriles que secundaron los puntos de vista de sus colegas ferroviarios, lo que, al fin, era un comportamiento previsible en el cuerpo de ingenieros. Por lo demás, una actitud semejante cabría esperar de los militares, algunos de los cuales eran ingenieros sin experiencia ferroviaria. Por otro lado, varios miembros tenían experiencia en Hacienda, como exministros (Pascual Madoz, Manuel Moreno López y Pedro Salaverría) o exdirectores generales de tributos indirectos. Solo había cuatro junteros relacionados con las fuerzas vivas del país que, a priori, estarían interesados en una extensa red ferroviaria como instrumento para el desarrollo. Eran Fermín Caballero, Rafael de Bustos, un ex cónsul del Tribunal de Comercio de Madrid y un miembro del Real Concejo de Agricultura, Industria y Comercio.

75 Barquín (2016): 293-294. 
Mención aparte merecen los cuatro representantes de las compañías ferroviarias: José Salamanca, José Campo, Manuel Bertrán de Lis e Ignacio de Olea (quien, como vimos, murió en 1865). Bajo circunstancias normales las compañías habrían sido favorables a la aprobación de un extenso plan de construcciones, lo que no dejaba de ser una buena alternativa al mejor escenario: la ausencia de un plan. Pero en 1865 el principal reto para esas compańías era la mera supervivencia. Es decir, lograr que el transporte fuera rentable o, al menos, no muy deficitario. Para conseguirlo cualquier medio parecía adecuado y ninguno mejor que la monopolización del mercado. De hecho, a raíz de la crisis las compañías abandonaron las guerras de tarifas e iniciaron una política de concertación que tendría muchas reediciones en los siguientes años ${ }^{76}$. Desde esta nueva perspectiva, para las compañías era preferible impedir la construcción de nuevas líneas que hiciesen competencia a las existentes. Esto atañía a las líneas transversales, pero no a las radiales o a las secundarias, que eran las que priorizaba la Comisión de Ingenieros.

Es significativo que, precisamente en enero y marzo de 1866, se presentara a la opinión pública y al Congreso una propuesta firmada por los representantes de todas las compañías ferroviarias. Solicitaban al Gobierno nuevas ayudas públicas a través del antiguo sistema de la garantía de interés, que legalmente seguía en vigor con la ley de 1855, pero que no se aplicaba porque todas las compañías habían preferido acogerse al de subvención kilométrica ${ }^{77}$. La Revista de Obras Públicas inmediatamente respondió con un larguísimo y demoledor artículo anónimo publicado en dos números, cuya autoría bien pudo corresponder a Gabriel Rodríguez. Según el mismo, la causa de la crisis ferroviaria estaba en el «principio fatal y ruinoso de las subvenciones [...] principio absurdo ante la ciencia económica ${ }^{78}$, que habría permitido la construcción de una red demasiado grande y poco rentable.

Así pues, el pleno de la Comisión Especial estaba inclinado a un "pequeño" plan ferroviario, es decir, el de la Comisión de Ingenieros. De hecho, fue más lejos. Propuso una red de 3331 kilómetros, lo que aún reducía en 483 los de aquella comisión (y en 70 los de la subcomisión interna formada dentro la Comisión Especial) ${ }^{79}$. En el proyecto de ley finalmente presentado no aparece la medición exacta de los kilómetros afectos a la primera y segunda categoría; solo se hace una indicación genérica de qué líneas serían prioritarias y cuáles no, pero podemos hacernos una idea a partir de la propuesta de la

\footnotetext{
Barquín (1997): p. 42.

Ferrocarriles Espańoles (1866).

78 Revista de Obras Públicas (1866), p. 50.

79 Comisión Especial (1867): 179.
} 
subcomisión que sí está cuantificada y que difería muy poco de esta. Las líneas de primera categoría serían 1477 kilómetros (frente a los 3034 de la Comisión de Ingenieros), siendo las de segunda categoría 1925 (frente a $780)^{80}$. Es decir, el texto finalmente aprobado no solo restringía severamente las propuestas iniciales, sino que, además, reducía considerablemente las líneas prioritarias.

El plan ferroviario finalmente aprobado por la Comisión Especial nunca se aplicaría. En septiembre de 1868 un nuevo pronunciamiento militar llevó al poder a una heterogénea coalición liderada por el Partido Liberal Progresista, con cuyo ideario se identificaban muchos ingenieros de caminos ${ }^{81}$. Sin embargo, la labor legislativa del Sexenio en materia de ferrocarriles desvirtuó ese programa. Es cierto que dio lugar a una Ley de Bases Generales de Obras Públicas de 14 de noviembre de 1868, firmada por José Echegaray, que consagraba el principio de libertad de empresa y la prohibición de subvencionar obras públicas realizadas por particulares, ayuntamientos y provincias (arts. 9, 11 y 18), pero haciéndose eco de la "desigualdad escandalosa»" ${ }^{82}$ existente en el reparto de las líneas, así como de la delicada situación financiera de las empresas, casi todas las medidas adoptadas en los siguientes ańos tomaron un rumbo prácticamente opuesto al propugnado desde el progresismo.

En primer lugar, y contradiciendo flagrantemente la ley de bases, pero con una oportuna antelación de siete días, se aprobó un plan de ayudas a las compañías ferroviarias, los llamados "auxilios», que venían a ańadirse a las subvenciones ordinarias y adicionales ya concedidas. A 31 de diciembre de 1872 las compañías habían recibido por este concepto 24,8 millones de pesetas, una cifra pequeńa, aunque tampoco desdeńable, con respecto al total de subvenciones ordinarias abonadas hasta entonces: 697,6 millones de pesetas $^{83}$.

Posteriormente, el 3 de febrero de 1870, se presentó un proyecto de ley sobre ampliación del plan general de ferrocarriles en el que, contradiciendo de nuevo la ley de bases, se contemplaba la concesión de una subvención de 60000 pesetas por kilómetro a un conjunto de líneas que sumaban 2069 kilómetros, aunque en los ocho años inmediatos solo se abordaría la construcción de 761 kilómetros. De todos modos, para salir adelante el proyecto de ley aún tuvo que asumir las rectificaciones impuestas por el Congreso dirigidas a

\footnotetext{
$80 \quad$ Ibid:: 151.

81 Sobre la recepción de la «escuela economista» en la sociedad y en el propio cuerpo de ingenieros, Martykánová (2016).

82 Mateo del Peral (1978): 125.

83 Memoria sobre las obras públicas en 1870, 1871 y 1872 (1873).
} 
ampliar la red. En resumen, la ley publicada el 7 de julio de 1870 contemplaba una red subvencionable de 3033 kilómetros, 1000 más que los del proyecto, pero 300 menos que los del plan de $1867^{84}$.

Sin embargo, este nuevo plan apenas tuvo aplicación. El 23 de noviembre de 1877, ya con la Restauración, se aprobó uno nuevo en el que las líneas subvencionables de servicio público cruzaban el territorio nacional de parte a parte. Y no solo eso: aún se afirmaba que otras más, especialmente las que atendieran los intereses mineros, podrían igualmente ser declaradas de servicio público. Así pues, el plan ferroviario de 1870, que era similar al de 1867, solo estuvo vigente durante siete años. En la práctica fue poco menos que inútil, pues su único sentido estaba en la ordenación de la construcción y la limitación de las subvenciones en el largo plazo. En sus primeros años, las secuelas de la crisis y la guerra civil paralizaron todos los proyectos. Luego, las pocas líneas que se concedieron hasta 1877 no coartaban los intereses de las compañías ferroviarias por cuanto que se limitaron a prolongar las ya previstas. Es significativo que las grandes líneas transversales, aún estando contempladas en ese plan de 1877 , no empezaran a construirse hasta la década de $1890^{85}$. Así pues, las compañías ferroviarias vieron satisfechas su doble aspiración de construir con subvenciones públicas y operar en condiciones de relativo monopolio.

\section{CONCLUSIONES}

A lo largo de las páginas anteriores hemos visto la pugna entre dos posiciones ideológicas sobre la construcción del ferrocarril en España. La primera era la sostenida mayormente por el liberalismo moderado, que enlazaba con el reformismo ilustrado. Tomaba como modelo el sistema francés de concesión administrativa y subvenciones públicas. La segunda era la del liberalismo progresista, también llamada «escuela economista», que tomaba como modelo

84 Los planes de 1870 y 1877, así como muchos anteproyectos, contemplaban varias nuevas conexiones con Portugal. Más allá de su limitado interés (desde la perspectiva española), existía una componente política: el iberismo, la aspiración a fortalecer las relaciones entre los dos países, incluso con la lejana pretensión de construir algún tipo de unión política. Lo cierto es que en Portugal existía cierto rechazo a esa aspiración y en España dominaba la indiferencia. Con el tiempo se acabaron construyeron varios accesos, lo que resulta coherente con la visión expansiva del ferrocarril español. Sobre la perspectiva portuguesa del programa constructivo espańol, Pereira (2017).

85 Barquín (2016): 312 
el sistema anglosajón de propiedad privada y ausencia de subvenciones. Había un tercer modelo, el belga, de construcción estatal de líneas principales que, por distintos motivos, era aceptable para las dos corrientes; incluso era la opción preferida, pero que nadie creía viable.

En su gran mayoría, el cuerpo de ingenieros de caminos estaba más cerca del liberalismo progresista que del moderado. Si en los primeros tiempos el prestigio de ingenieros como Subercase aún pudo inclinar la balanza hacia el moderantismo, la aparición de una segunda generación representada por Ardanaz, Rodríguez, Page, Retortillo o Echegaray, afianzó definitivamente al progresismo. Protegidos por su condición de funcionarios, expresaron con libertad sus puntos de vista, que a veces eran contrarios a los intereses de las compañías ferroviarias y el propio Estado. Los ingenieros progresistas estuvieron presentes en todas las comisiones parlamentarias relevantes, desde la Olózaga de 1850 hasta la Especial de 1867, y en ellas defendieron con éxito una política de transporte presidida por una visión realista del tráfico y los recursos públicos.

Con todo, su autoridad no alcanzó a ciertas cuestiones sensibles. El legislador optó por un sistema de concesiones administrativas que, en un primer momento, incluso admitía las provisionales. Mediante la no planificanción, se implantó un sistema de subvenciones públicas casi irrestricto. Cuando en 1870 se aprobó el primer plan ferroviario, la coyuntura del momento hizo que no tuviera mayor aplicación. Siete años más tarde, un nuevo y extenso plan puso fin a cualquier intento de ordenación racional y restricción de las ayudas públicas. En otras palabras, los ingenieros progresistas españoles tuvieron que aceptar un modelo de desarrollo ferroviario diferente, si no contrario, al que habían propuesto.

El resultado fue una red ferroviaria que cumplía diversos objetivos, pero de forma insatisfactoria. Era una red extensa para la riqueza y población del país, aunque insuficiente para satisfacer todas las demandas sociales. Se construyó mediante el auxilio de unas subvenciones generosas sobre las que hubo un control público insuficiente. La red otorgaba a las compañías ferroviarias un cierto monopolio gracias a la disposición preferentemente radial de las líneas, lo cual les permitía obtener una rentabilidad magra, acorde con los reducidos tráficos ${ }^{86}$. Esa extensa red era deficiente en muchos aspectos porque la orografía era complicada y las soluciones técnicas empleadas en la construcción fueron ahorrativas, pese la generosa participación del Estado ${ }^{87}$. En fin, una red ferroviaria con algunas fortalezas, pero con muchas debilidades.

86 Cuéllar (2018) 537-540

87 Franch-Auladell et al. (2014) y Herranz (2008) 


\section{Bibliografía}

Alcaide, R. (1999). El ferrocarril en España (1829-1844): las primeras concesiones, el marco legal y la presencia de la geografía en las memorias de los anteproyectos de construcción de las líneas férreas. Biblio 3W, 190. Disponible en http://www.ub.edu/geocrit/ b3w-190.htm.

Barquín, R. (1997). Transporte y precio del trigo en el siglo xix: creación y reordenación de un mercado nacional. Revista de Historia Económica, 15 (1), 17-48. Disponible en: https://doi.org/10.1017/S0212610900006297.

- (2012). Segovia versus Ávila: la conexión ferroviaria entre Madrid y la Cuenca del Duero (1845-1865). Investigaciones de Historia Económica, 8 (3), 144-153. Disponible en: https://doi.org/10.1016/j.ihe.2011.12.013.

- (2016). Castillos en el aire, caminos de hierro en España. La construcción de la red ferroviaria española. Revista de la Historia de la Economía y la Empresa, 10, 289-317.

Castellvi, D. y Barquín, R. (2018). Las subvenciones adicionales en la compañía ferroviaria MZA. Revista de Historia Económica, 36 (3), 457-480. Disponible en: https://doi. org/10.1017/S0212610918000046.

Cien años del ferrocarril en España (1948). Madrid: Comisión Oficial para la Conmemoración del Primer Centenario del Ferrocarril en España.

Comín, F. (1988). Hacienda y economía en la España contemporánea (1800-1936). Madrid: Instituto de Estudios Fiscales.

(1996). Historia de la Hacienda Pública, II. España (1808-1995). Barcelona: Crítica. (2016). Las crisis de la deuda soberana en España (1500-2015). Madrid: Catarata.

— , Martín Aceña, P., Muñoz Rubio, M. y Vidal Olivares, J. (1998). 150 años de historia de los ferrocarriles españoles. Madrid: Anaya.

Comisión Especial (1867). Memoria presentada al Gobierno por la Comisión especial encargada de proponer el plan general de Ferrocarriles. Madrid: Rivadeneyra.

Compañía de Ferrocarriles del Norte de España (Norte) (1863-1867). Actas del Consejo de Administración. Madrid: Museo del Ferrocarril,Archivo Histórico Ferroviario.

Congreso de los Diputados. Comisión de Ferro-carriles (1850). Información parlamentaria hecha por la comisión de ferro-carriles nombrada por el Congreso de los Diputados en 10 de Enero de 1850. Madrid: Imprenta Nacional.

Cordero, R. (1978). La construcción. En M. Artola (dir). Los ferrocarriles en España, 1844/1943. 1. El Estado y los ferrocarriles (pp. 197-265). Madrid: Banco de España.

Cuéllar, D. (2010). Et Stephenson dit «Non»: capitaux britanniques et chemins de fer en Espagne. Économies et Sociétés. Historie Économique Quantitative, 44 (6), 949-986. (2018). Razones y maravedíes: una mirada crítica a los negocios del ferrocarril en España (1844-1943). Hispania Nova, 16, 522-557. Disponible en: https://oi.org/10.20318/ hn.2018.4047.

Ferri, M. (2015). El ejército de la paz. Los ingenieros de caminos en la instauración del liberalismo en España (1833-1868). Valencia: Universidad de Valencia.

Ferrocarriles Españoles (1866). Exposición y proyecto de garantía de interés por el Estado a los Ferrocarriles Españoles. Madrid: Minuesa. 
Fontana, J. (1971). La quiebra de la monarquia absoluta. La crisis del Antiguo Régimen en España. Barcelona: Ariel.

(1973). Hacienda y Estado en la crisis final del Antiguo Régimen, 1823-1833. Madrid: Instituto de Estudios Fiscales.

Franch-Auladell, X., Morillas-Torné, M. y Martí-Henneberg, J. (2014). The railway network and the process of population concentration in Spain, 1900-2001. Revista de Historia Económica, 32 (3), 351-379. Disponible en: https://doi.org/10.1017/S0212610914000160.

Gómez Ochoa, F. (2007). El liberalismo conservador español del siglo xIx. Historia y Politica, 17, 37-68.

González Arnao, J., Rodríguez, G. y Torres, L. (1866-1867). Memoria sobre los medios de reducir los gastos de primer establecimiento de los ferrocarriles secundarios. Disponible en: http://bdh-rd.bne.es/viewer.vm?id=0000225916\&page=1.

Herranz, A. (2008). Infraestructuras y crecimiento económico en España (1850-1935). Madrid: Fundación de los Ferrocarriles Españoles.

Junta Consultiva de Ingenieros de Caminos, Canales y Puertos (1864). Informe y anteproyecto del plan general de ferrocarriles.

Larrinaga, C. (2005). La "Concesión Vascongada» y los antecedentes de la línea ferroviaria del Norte (1844-1855). Espacio, tiempo y forma. Serie V, Historia contemporánea, 17, 67-92.

Marcoartu, A. (1854). La Revolución y las obras públicas. Revista de Obras Públicas, 2, t. I (16), 205-206.

Martín Rodríguez, M. (2006). La Economía Política en la Escuela Especial de Ingenieros de Caminos, Canales y Puertos, 1855-1936, estudio introductorio a C. Orduña y Zarauz. Lecciones de Economía Matemática (pp. 9-109). Madrid: Fundación de las Cajas de Ahorros.

Martínez-Val, J. M. (2001). Un empeño industrial que cambió a España, 1850-2000. Siglo y medio de ingeniería industrial. Madrid: Síntesis.

Martykánová, D. (2007). Por los caminos del progreso. Ayer, 68, 193-219.

- (2016). Remover los obstáculos. Historia y Política, 36, 49-73. Disponible en: https:// doi.org/10.18042/hp.36.03

— y Gilarranz, A. (2020). Building Public Works, Building the State: infrastructures as a way of redefining the legitimacy of government in the mid-nineteenth century Spain. History and Technology (en prensa).

Mateo del Peral, D. (1978). Los orígenes de la política ferroviaria en España (1844-1877). En M. Artola (dir.). Los ferrocarriles en España, 1844/1943. 1. El Estado y los ferrocarriles. (pp. 29-159). Madrid: Banco de España.

Memoria sobre las obras públicas en 1867, 1868 y 1869 (1870). Madrid: Rivadeneyra.

Memoria sobre las obras públicas en España en 1870, 1871 y 1872 (1873). Madrid: Minuesa.

Muñoz, M. (2018). Los "grandes debates» de la historiografía ferroviaria española y su influencia en la historiografía general y económica. Revista de la Historia de la Economía $y$ de la Empresa, 12, 89-122.

Nadal, J. (1975). El fracaso de la Revolución industrial en España, 1814-1913. Barcelona: Ariel.

Olazábal, E., Barquín, R., Álvarez-Palau, E. J. y Macías Muñoz, M. O. (2019). Catálogo digital de cartografía urbana contemporánea en España, 1800-1950. Biblio3W. Disponible en: http://ciudadyferrocarril.com/cartografia_urbana. 
Pan-Montojo, J. (2006). El progresismo isabelino. En M. Suárez Cortina (ed.). La redención del pueblo: la cultura progresista en la España liberal, (pp. 183-208). Santander: Universidad de Cantabria.

Pereira, H. S. (2017). The technodiplomacy of Iberian transnational railways in the second half of the nineteenth century. History and Technology, 33 (2), 175-195. Disponible en: https://doi.org/10.1080/07341512.2017.1317847.

Ramos Gorostiza, J. L. y Martínez Vara, T. (2008). Las ideas económicas de los ingenieros de caminos: la Revista de Obras Públicas (1853-1936). Investigaciones de Historia Económica, 11, 9-38. Disponible en: https://doi.org/10.1016/S1698-6989(08)70152-8.

Reinoso, M. M. (1853-1857). Política administrativa del gabinete Bravo Murillo, en el marco de Fomento. Madrid: Imprenta de Tejado.

Retortillo, A. (1853). Caminos de hierro. Revista de Obras Públicas, 1, t. I (3), 25-29.

Ringrose, D. R. (1972). Los transportes y el estancamiento económico de España (1750-1850). Madrid: Tecnos.

Romeo, M. C. (1998). Lenguaje y política del nuevo liberalismo: moderados y progresistas, 1834-1845. Ayer, 29, 37-62

Rumeu de Armas, A. (1980). Ciencia y tecnología en la España ilustrada. Madrid: Turner.

Sáenz Ridruejo, F. (1990). Ingenieros de caminos del siglo XIX. Madrid: Colegio Oficial de Ingenieros de Caminos, Canales y Puertos.

- (1993). Los ingenieros de caminos. Madrid: Colegio Oficial de Ingenieros de Caminos, Canales y Puertos.

Santos, L. A. L. dos (2011). Política ferroviaria ibérica de principios del siglo XX a la agrupación de los ferrocarriles (1901-1951). [Tesis doctoral inédita]. Universidad Complutense de Madrid.

Schram, A. (1997). Railways and the formation of the Italian state in the nineteenth century. Cambridge: Cambridge University Press.

Tortella, G. (1982). Los orígenes del capitalismo en España. Madrid: Tecnos.

Wais, F. (1974). Historia de los ferrocarriles españoles. Madrid: Editora Nacional. 